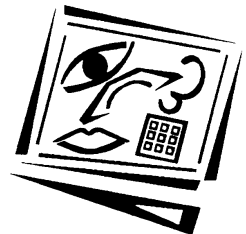

\title{
Identifying the factors that influence computer use in the early childhood classroom
}

\author{
Suzy Edwards \\ Monash University
}

\begin{abstract}
Computers have become an increasingly accepted learning tool in the early childhood classroom. Despite initial concerns regarding the effect of computers on children's development, past research has indicated that computer use by young children can support their learning and developmental outcomes (Siraj-Blatchford \& Whitebread, 2003; Yelland, 1999). Whilst this has been established, more recent research has begun to focus on the social and educational context in which computers are used in early childhood education (Brooker, 2003; Plowman \& Stephen, 2005). An aspect of this focus involves understanding how educators conceive of, and use, computers in early childhood education classrooms. This paper reports the findings from a study aimed at examining twelve Victorian early childhood educators' experiences integrating computers into the early childhood classroom. The paper focuses on the factors the educators saw as influencing computer use in their classrooms. A total of nine factors were identified as important. The top four of these factors were examined in more detail, these being 1) the need for educators to have operational knowledge of the computer; 2 ) the need to select software appropriate to the children's learning and developmental needs; 3 ) the need for children and educators to have access to current and reliable technology; and 4) the need to actively consider where (and why) the computer would be located in the classroom.
\end{abstract}

\section{Theoretical background}

Information and communication technologies have become an accepted part of most educational settings during the last twenty years (Anderson, 1999, p. 327). Despite initial debate regarding the developmental suitability of computers for young children, computers are being used with increased frequency within many early childhood educational settings (childcare or preschool programs for children aged 3-5 years) across Australia, the United Kingdom and the USA (Stephen \& Plowman, 2003). Although early concerns regarding young children's computer use with respect to their cognitive, language and social development were expressed (Barnes \& Hill, 1983), later research suggested these fears were unfounded. Rather, the 
research indicated that exposure to open ended; constructivist based computing experiences tended to support children's developmental growth (Goodwin, Goodwin \& Garel, 1986; Papert, 1980; Wright \& Samaras, 1986). In addition, further research suggested that children's developing social and language abilities could be supported in those situations in which computer use was emphasised as a collaborative activity (Genishi, McCollum \& Strand, 1985; Muller \& Perlmutter, 1985). Since the early 1990s the literature concerned with early childhood computing has served to emphasise that computers represent a valuable learning experience for young children when utilised in a pedagogically appropriate manner (Clements \& Sarama, 2002; Finegan \& Austin, 2002; Rivera, Galarza, Entz \& Tharp, 2002; Stephen \& Plowman, 2003; SirajBlatchford \& Whitebread, 2003; Yelland, 1999). The development of position statements with respect to this argument by key national early childhood foundations (for example the National Association for the Education of Young Children [1996] and the Australian Early Childhood Association [1999]) have served in turn to highlight the efficacy of this particular view. As Clements and Sarama (2002) describe, the central focus with respect to computing in early childhood education is no longer whether or not they should be used:

We know that computers are increasingly a part of preschoolers' lives. From
80 percent to 90 percent of early childhood educators attending the annual
conference of the National Association for the Education of Young Children
report using computers. Such use is no surprise; research on young children
and technology indicates that we no longer need to ask whether the use of
technology is developmentally appropriate (Clements \& Sarama, 2002, p.
340).

It is on the basis of this belief that more recent research has began to shift from an examination of the effects of computer use on young children, to encompass consideration of other issues related to their integration in the early childhood classroom. For example, as Clements (1999) identified:

Research has moved beyond the simple question of whether computers can help young children learn. They can. What we need to understand is how best to aid learning, what types of learning we should facilitate, and how to serve the needs of diverse populations ... not every use of technology, however, is appropriate or beneficial. The design of the curriculum and social setting are critical (Clements, 1999, p. 93).

Clements' identification of the broader issues associated with early childhood computing is important and suggests that recent research developments in the area, such as the focus on teacher perceptions of computer use in early childhood education, and issues associated with the integration of computers into early childhood classrooms are becoming increasingly important (Brooker, 2003; Plowman \& Stephen, 2005). A 
significant feature of this research has been the emphasis on examining the context of computer use rather than a focus on the relationship between computer use and children's consequent development. The shift in focus has served to broaden conceptions of computer use in early childhood education to include reference to early childhood teachers, their beliefs, understandings and confidence regarding not only the integration of the computer within their classrooms, but also their ability to relate the technology to existing pedagogical approaches to early education.

Early childhood education is largely characterised by a play based tradition, in which educators draw on a range of developmental and constructivist learning theories to inform curriculum decision making. Learning experiences utilise a range of natural play materials including blocks, sand, water, paper and paint which educators have manipulated in order to support children's learning and development (Brooker, 2003). As such, early childhood educators are invested with a great deal of responsibility for developing the curricula and identifying the learning experiences children will experience within a given setting. This situation likewise applies to the integration of computers within an early childhood classroom, with teachers needing to decide how, when and where a computer will be used to support children's learning in relation to existing pedagogical and theoretical imperatives. In this sense, the continued development of research into early childhood computing should necessarily consider the perspective early childhood educators hold as practitioners in the field and as users of the very technology under examination.

Although newly emerging, research conducted from this perspective is beginning to explore how educators perceive and utilise computers in the early childhood classroom. For example, Sandberg (2002) examined the conceptions thirteen Swedish preschool teachers held regarding computer use in their classrooms, in relation to their understandings of play as a central informant to the early childhood curriculum. Sandberg's findings indicated that the teachers' believed the computer fitted their understandings of children's play, and that it held potential as a tool to enhance children's development. For these teachers, the computer was viewed as an instrument for learning, although this view was complicated by issues such as time and access to resources which were viewed as barriers to utilising the tool to its full potential (Sandberg, 2002, pp. 250256).

Another study by Filipenko \& Rolfsen (1999) likewise examined the issues associated with computer use from the educator's perspective. This investigation was conducted as a case study of one teacher working in a Canadian preschool and focused on exploring the issues that were related 
to the decision to utilise a computer in the early childhood context. Filipenko \& Rolfsen (1999) found that the decision was influenced by four main issues, including those associated with equipment requirements, the need to learn how to use the computer, the need to manage the computer centre in the classroom and the process associated with the selection of appropriate software. Other research tends to support these findings, suggesting that significant factors related to early childhood educational computing include teacher knowledge regarding the basic operation of a computer, issues associated with the selection of appropriate software for young children, access to up to date technology, and consideration regarding the physical location of a computer within the classroom (Haugland, 1997; Judge, Puckett \& Cabuk, 2004; O’Rourke \& Harrison, 2004).

These findings indicate that Clements' (1999) suggestion that issues beyond the 'developmentally appropriate' question regarding computer use in early childhood education are of significance to the field. The extent to which these factors are of common concern to early childhood educators requires continued consideration in order to inform the research and literature base aimed at articulating best practice computer use in early childhood education. The findings reported in this paper aim to build on existing research regarding the factors that influence computer use in early childhood education by examining the issues early educators consider important when integrating computers in their classrooms. Accordingly, the research question of focus for this paper is: "What are the main factors that early childhood educators consider of importance when integrating computers in their classrooms for use by young (3-5 years) children?"

\section{Methodology}

The study was conducted as a qualitative investigation aimed at determining how and why early childhood educators integrated computers into their classrooms. Twelve early childhood educators drawn from early childhood settings within inner and eastern metropolitan Melbourne participated in the study. Six participants were from government funded sessional preschools catering for children aged 4 years and over; and six from early learning centres attached to independent schools catering for children aged 3-5 years in a long day care setting. Participants were selected using purposeful sampling, with each of the participating educators holding a minimum qualification at the Bachelor of Education level; having at least two years experience in the field and at least 8 months experience using computers in their programs. Selection criteria were developed to ensure that participants had a similar level of training, a minimum amount of teaching experience in the field and some exposure to computer use in their classrooms. Eight months was selected as the base 
level for computer use in early childhood education, given difficulties associated with locating educators meeting the first two criteria and having also integrated computers in their programs.

Ten of the participating educators had a computer for the children's use located in their classrooms as well as access to a computer for professional use in their office. Two of the teachers had access to only one computer which was located in their office. In these settings children would be supervised in the office when the teacher wished them to use the computer. Each centre catered for approximately 15-20 children. Of the twelve teachers, one teacher had attended an 'introduction to computers' course which covered basics such as turning the computer on, saving files and opening and closing programs. The remaining teachers had self taught computer skills and none of the teachers had attended professional development courses on computer use in early childhood education.

Data were collected using a pre-developed interview schedule in which educators were asked to respond to a series of questions regarding their decision to implement a computer in their classroom and detail the factors they considered of importance in this process. All interviews were conducted separately at the educators' centres during November 2001, taking on average one hour per interview to complete. Interviews were tape recorded and transcribed for later analysis. The interview schedule was developed following the implementation of a pilot study investigation aimed at examining early childhood educators' perceptions of developmentally appropriate multimedia (Edwards, 2001).

The interview schedule focused on the educators' use of a computer in their classroom and contained questions including; what were your early thoughts regarding how the computer would fit into your curriculum? How did you consider the computer in relation to your understanding about early childhood education and developmentally appropriate practice? Do you think your understanding about developmentally appropriate practice informs your decision making about how to use the computer in your classroom? If you were to advise a teacher new to using computers in early childhood education, what main issues or factors, would you tell her need to be considered in order to integrate a computer into the classroom? The interview schedule was not tested prior to its use in the study. This, combined with the small sample number suggests that findings reported in this paper are largely of descriptive and exploratory value. This paper focuses on detailing the educators' responses to the latter part of the interview, namely the hypothetical question in which educators were asked to describe the advice they would give to a colleague new to using computers in early childhood education. The aim of this question was to determine the main factors that early childhood educators 
considered of importance when integrating computers in their classrooms for use by young children.

\section{Data analysis and findings}

The transcribed data were analysed using the qualitative data analysis package NVIVO. Here the main themes arising from the data were identified using the using the built in coding system. Following the coding of each transcript, the process was repeated to ensure that themes identified later in the first coding of the data were applied across all twelve transcripts. Following the re-coding of data the analysis tool was utilised in order to develop a visual representation of the factors found to be of importance to the educators when implementing computers in their classrooms. The analysis revealed that this was characterised by nine factors. The search facility was employed to determine the number of codes applied to each of these factors. The factors are listed in order of importance in Table 1. Factors 1-4 are highlighted for further discussion as the most frequently cited factors of importance to the educators having registered ten or more codes per factor during the search process.

Table 1: The most frequently cited factors of importance (in order of importance) to early childhood educators when implementing a computer into their classrooms

\begin{tabular}{|l|l|}
\hline Factor & \multicolumn{1}{|c|}{ Description } \\
\hline One & $\begin{array}{l}\text { The need for educators to have knowledge of the various components } \\
\text { (including hardware and software) of computer technology and how these } \\
\text { are used }\end{array}$ \\
\hline Two & $\begin{array}{l}\text { The selection of software for use in the classroom that is appropriate to } \\
\text { children's developmental and learning needs }\end{array}$ \\
\hline Three & $\begin{array}{l}\text { Access to current and reliable technology (including hardware and } \\
\text { software) }\end{array}$ \\
\hline Five & $\begin{array}{l}\text { Active consideration of where the computer should be located in the } \\
\text { classroom }\end{array}$ \\
\hline Six & $\begin{array}{l}\text { The need to teach children how to use the computer and its associate } \\
\text { peripherals }\end{array}$ \\
\hline Seven & $\begin{array}{l}\text { Considering the educational or intended purpose in using the computer } \\
\text { within the context of the broader curriculum }\end{array}$ \\
\hline Eight & Assisting children to share and/or take turns in using the computer \\
\hline Nine & $\begin{array}{l}\text { Ensuring that children have the necessary fine motor skills to operate the } \\
\text { computer effectively }\end{array}$ \\
\hline
\end{tabular}

As indicated in Table 1 the educators' use of computers in the early childhood classroom were influenced by nine factors. The findings relevant 
to the top four factors are presented in greater detail and the implications of these findings considered in the discussion section of the paper.

\section{Discussion}

\section{Factor one: knowledge of computer components and use}

The educators' identified their level of computing knowledge as a key factor of importance when integrating a computer into their classrooms. This was one of the first issues raised by the educators in response to the hypothetical question regarding how they would advise a colleague planning to integrate a computer in her classroom. Here a typical response would include reference to the educators' actual familiarity with computers and their associated components, such as the software and hardware. For example, one teacher emphasised the manner in which educators needed to be 'familiar with the computer, to have a basic understanding of it' (T1). When asked to explain further, a 'basic understanding' was defined as such:

Turning it on and shutting down a file and rebooting if you have to and umm, just working with some of the software first so you can know generally what they [the children] have to do (T1).

For this teacher, reference to a 'basic understanding' was further defined by her attitude towards the computer and recognising that she herself could learn much from the children:
But really for me the children are quite confident and they can teach me how to do it, so I think just take risks, you know, it doesn't matter and don't assume it has to be done a certain way, allow the children to, I guess not to let them be panicky about it and if something happens, 'oh well we have lost that bit of work and need to start again'. So I think you need to feel free to experiment (T1).

The reference to understanding how to utilise the technology and respond to its use in the classroom was likewise expressed by teacher two (T2). Here, she made reference to the need to understand some of the basic operational issues associated with the computer, and also the need to remain open to further learning opportunities, even if these were provided by the children themselves:

Definitely their [teachers'] understanding of the technology is an important thing and how comfortable teachers are. I know that working within a school environment, here that we have a couple of staff who admittedly aren't working with young children who have very little experience with computers, and they take their kids in the lab here. I don't take my class in the lab here because it would be an absolute disaster but some teachers don't have that confidence or the understanding of how it all works to do that. If 
they had more of a background and understanding themselves personally, and felt confident in going out and letting the kids have a go, knowing that there isn't really anything that you can do wrong, just get out there, then that will influence how they work with the computers (T2).

For these teachers, awareness of how to use the computer itself was linked to its use in the classroom. As another teacher described, being comfortable with using the technology was linked to her ability to teach its use to the children, and so "if you are not familiar with something [it is hard to] confidently pass it on to others" (T3). In this respect, the manner in which the computer was used in the early childhood classroom was quite strongly linked to the educator's understanding of how it worked and what it was capable of achieving. This factor was further explored by teacher four, who noted that two different teachers with different understandings of the technology would likely effect different learning experiences for the children:

If you had two teachers with different levels of knowledge they could provide an entirely different program for the same need because one might know a computer better than the other and therefore access ways and means of assisting the child and their development through the computer. But the other teacher might then take them through a different avenue using different tools to teach them a similar skill (T4).

The emphasis on teacher knowledge, with respect to the use of the computer, was a factor emphasised by T3. Here, T3 explained how her continued experience with the computer and its associated hardware and software had influenced the manner in which she was able to support and extend the children's learning within the classroom context:

It (using the computer) has been a big learning curve for me, and I think having the attachments, like the scanner and things, has meant we can use it in a variety of different ways and we are using Photoshop, editing photos as well which is like when I take photos of them with the digital camera. I am hoping to, as I get to know that program more, get them [the children] to, cut out themselves and maybe put them onto a background of their drawing that they have done, or something like that, that they can actually do as a really different thing (T3).

As T3's description indicates, greater awareness and familiarity with the computer, its associated components and how these may be used, served to influence its application in the classroom. As a factor, familiarity with the technology itself was clearly an issue of concern that these educators would express to a colleague intending to utilise computers in the early childhood classroom. These findings suggest that early childhood educators' levels of computing knowledge contribute to the success with which computers can be integrated within an early childhood classroom. Judge et al. (2004) have argued that unless early childhood educators have an appropriate 
understanding of how the technology works, they will be unable to effectively integrate the computer into the learning environment provided for young children (p.387). Interestingly, Judge et al. (2004) note that access to professional development for teachers actually represents an access and equity issue for young children, arguing that physical access to a computer in an early childhood setting will not guarantee appropriate learning for young children unless their teachers "have the knowledge and skills to integrate technology into meaningful activities of interest and relevance to children" (p. 387).

For some teachers in this study, such knowledge referred to basic skills such as turning the computer on and off and being able to load software. However, for T3, growing knowledge of how to use the computer and its associated hardware and software resulted in the situation described by Judge et al., in which the technology was being utilised to support children's participation in meaningful learning experiences. Whilst this teacher was self taught, with her computing experience described as a "big learning" curve, the need for continued professional development in the area is necessary to ensure the appropriate integration of computers in early education. In this context, professional development needs to include reference to key computing skills, and needs also to support educators in understanding how a computer can be related to the traditional play based early childhood curriculum. Haugland (1999) has identified four stages of professional development for early childhood teachers learning to use computers in their programs, including practice experiences with computers; participation in workshops; exposure to models and mentors; and finally, supervisory follow up support (p. 30). This model of professional development highlights the need for educators to have knowledge of both how the computer actually works and how to relate it to their practice within the early childhood context.

\section{Factor two: software selection}

The selection of software for use in the classroom was a factor of importance to the educators and was linked to the actual learning they believed would come from the children's use of the computer. In part, this factor was related to the first in which knowledge of the computer itself was deemed an important issue relative to its implementation in the classroom. This relationship was quite clearly articulated by teacher five (T5) who described her ability to select software for use in the classroom as limited by her knowledge of the computer's specifications:

I don't really know enough about it, I don't even know how to buy software for our computer. I wouldn't even know how to get software. I don't even understand when it tells you about you know the RAM and things, I have 
no idea what that means, so I wouldn't be able to buy software for it, I am just getting what people [donate], what we get (T5).

Despite this frustration, teacher five still viewed the selection of software as a pedagogical factor of importance when using a computer in the classroom. Although hampered by her lack of understanding regarding the computer's specifications she nonetheless detailed the importance of selecting software appropriate to the children's learning and developmental needs from that actually available to her:

So I do decide from what we have got, depending on, well I suppose, something that has an interactive component that the children can work interactively (T5).

A similar emphasis on children's interactions with the software was noted by another teacher (T6), who described the selection of appropriate software as an important factor to consider when implementing computers in the classroom. Here, the program KidPix was identified as software considered appropriately interactive for use by young children:

Believe me, if I was selecting software I would be looking more for, there is a program it is like a creative art [KidPix] and we wanted to get that because I had seen that somewhere else and thought 'yeah this looks really good and it is much more interactive and has three-d drawing'. It is just a different activity and drawing on the computer it is not, like them going into a trance in the same way as the other sorts of games (T6).

The notion of interactivity with respect to software selection was important and one noted by a number of the educators:

It is important that it [the software] is not such a structured thing, that it is not JUST there for the children to look at this computer screen and that it is a more active experience (T2).

I suppose one thing I would say is whether you want to introduce something animated first, or something not animated because in my experience if you want to do something animated it is like a movie and they just sit there (T7).

You need a different range of software that will appeal to a wide range of kids, not just like the typing up on the keyboard, letters and things like that, but also like colours. I just call it free art basically, yeah the free art stuff (T8)

Here the selection of software for use in the classroom was linked quite strongly to the idea that the children needed to interact with, rather than respond to, the computer for the experience to have educational merit. This was an idea explored in more detail by T4 who noted that the software needed to engage children to support their learning: 
Your software of course is equally important, you have got to get things that are pertinent, like you have got your draw programs, where you can transfer things and there's things where you can transfer from a drawn picture on a screen onto a piece of paper and print it and then it can be out here and there are all sorts of accessories to these things that you can then utilise, so we can engage more in it (T4).

The degree of interactivity enabled by a program was not the sole consideration in relation to the selection of software, with issues associated with the age appropriateness of the program also of importance. Here the educators noted that the activity enabled by the software needed to be appropriate to the children's abilities and levels of computer experience:

When I look at computer games, and I don't know much about any of them, I will go into shops and look at the age group and the type of activities and how it fits in with my program. It comes into the developmentally appropriate age group for the children, and I also try and get different levels so there are some activities for children who are, it might be a bit younger for them because they have never used a mouse, so just getting used to a mouse (T9)

Choosing the software, the program, you have to think about the age appropriateness, age appropriate programs that is what I would be thinking of, so with the software you have to explore the age appropriateness, and the difficulties for the children (T12)

For T10, age appropriateness formed a similar concern to that expressed by T9 and T12 in their selection of software for use in the early childhood classroom. However, for this teacher the selection of software was governed by a range of issues, in addition to age appropriateness, usability and the expression of gender stereotypes:

Basically the underlying philosophy and policy is that it has to be educationally valuable, and developmentally appropriate for that age. We have gone for stories, although that depends on the length of the story; we use pictorials, but we want them bright, clearly seen, with a bit of text depending on how long the [child's] concentration span is. Obviously, well it is obvious to us that there is no violence, no inappropriate language, I guess a balance of gender identity or representation (T10).

The selection of appropriate software was clearly of concern to the educators as a factor related to the integration of computers within the classroom. In the main, this factor appeared to be defined by the educators' beliefs about young children's learning. Here, reference to the degree of interactivity afforded by the software served to comprise much of the discussion surrounding the identification of software selection as a factor. In addition to the notion of interactivity, there were the issues associated with age appropriateness and gender identity in the selection of software 
considered suitable for use in the classroom. Research by Haugland (1997) has suggested that software selection forms an important component of computer use in early educational settings. Haugland surveyed 195 early American early childhood educators and found that teachers valued software that was perceived as user friendly, creative, developmentally [age] appropriate and interactive (p. 10). Previous research has similarly highlighted the role interactive and open ended software can play in supporting young children's learning and development in early childhood educational contexts (Clements, 1999; Finegan \& Austin, 2002; Yelland, 1998, 1999).

In this study, interactivity was valued by the educators, with interactivity defined in terms of the children's engagement with the software in preference to their just 'sitting there'. The extent to which this preference for engagement and active interaction with the software extends from the educators' existing understandings of the early childhood curriculum cannot be determined from this study. However, the question is one worthy of further examination. For example, to what degree do traditional values and pedagogies in early childhood education serve to influence what teachers consider appropriately engaging and interactive? Teachers six and eight tended to define this in terms of the freedom and creativity enabled by art based programs such as the KidPix software over software described by other teachers as 'movie like' or 'too structured'. The relationship between traditional values and pedagogies in early childhood education and computers is complex and one noted by Brooker (2003) as defined by "nearly two centuries of early education in which children roam freely either outdoors surrounded by nature, or indoors, surrounded by natural objects such as blocks, sand and water, paint papers and plants (pp. 262-263). This perspective paints tension between the traditional play based values informing early childhood education and the potential displacement of these beliefs via the computer. For the educators in this study, the tension was addressed by selecting software they considered congruent with their pedagogical beliefs regarding the need for children to be actively involved in their learning.

\section{Factor three: Access to current and reliable technology}

Ready access to current and reliable technology was identified as the third factor comprising the educators' recommendations regarding the integration of a computer within their classrooms. Although a seemingly obvious factor, a number of educators reported circumstances in which they were working with dated and at times faulty technology. The frustration caused by computers 'freezing' or working too slowly was evident, with teacher nine describing this in terms of a 'lost' teaching moment: 
You've got to have good computers, that's the other issue, because I remember going back, initially we had one computer that wasn't working very well and this was off site and it would take a long time to load and a long time to process and the learning moment had escaped it had gone, so it really also depends on your actual type of machines (T9)

For this teacher the use of the computer in her teaching was related to the speed with which it could respond to the children's learning needs. The time taken for the information to load and be processed was directly related to the learning moment with which she wished to use the computer in the first instance. To be effective, the computer itself needed to be 'good'; with good defined in terms of reliability and speed. This issue was identified by teacher eleven who described her experience in using a computer that tended to shut down without obvious reason. Eventually, it was simply considered easier to avoid using the computer at all:

We got a second hand one, which kept on shutting down all the time, which is another reason why I just gave it up, you need one that works properly. The dad has taken it away to fix it, but one that works would be very good. It was a shame because he donated it and he fixed it up for us and then every time, one person could have a turn but then it froze, and it was like, 'well that is it, no one else can have a turn' and I don't know what to do with it. So when it is up and going [it is good], but it is important I think to have the computer running efficiently (T11).

The need for a reliable computer was a sentiment similarly expressed by teacher eight, whose advice to a colleague intending to use a computer in her classroom was summed up as "finding a computer that is functional, that is really good and functional and beneficial for your kids". For this teacher 'beneficial' was defined not only in terms of using the computer as a delivery platform for software. Instead, she referred to the possibilities enabled by having access to a scanner, whereby she could scan the children's work into the computer so that they could explore and manipulate the images digitally: "There is so much that you can do, like with a scanner and the children's work" (T8)

Access to peripherals such as scanners and/or digital cameras was an issue raised by other educators who described how they envisioned such equipment being used, and its ability to extend computer use in the early childhood classroom beyond a reliance on commercial software:

I guess one thing, one of our accomplishments if you like, is with the digital cameras and making that learning, it might be outside, you have taken a photo of a group time, inside or outside and then we can put it obviously for the children to delight in and they begin to share in that dialogue and of remembering 'this is what happened when we did this, this and this (T10) 
A digital camera would be nice, that would be beautiful actually, because we take a lot of photos in our kinder all the time and I guess to have a digital camera and to print it out we could do things like Mother's day cards, or things that you could do really quickly, like the children being able to see what they have done straight away (T9)

Access to more enabling technology such as the digital camera was linked by these teachers to the immediacy of the children's learning, and the ability to initiate discussion about events that had just occurred. The link between the immediacy offered by the digital camera and the children's learning was an issue explored in more detail by teacher five who described how she envisioned its use in her classroom:

I would love one; we are saving up for a digital camera. We have got some photos, we went on an excursion, and I just think the difference between the way we do it now with my camera and it takes a week to get the photos and process them. I would love to do that next year, and that will be a fund raising priority. It is like when we went to the fire station, they would have seen those [photos] that afternoon and been able to talk about them, just the immediacy, it is fresh in their minds, they are excited by the experience still. Yeah a week later, I mean it is nice to see the photos a few days later but, just the freshness and the excitement of having it fresh in their minds that would be good (T5)

The educators' reference to the educational potential enabled by technology such as scanners and digital cameras is indicative of an awareness regarding the manner in which such technology may be utilised to support their current practices. Siraj-Blatchford and Whitebread (2003) argue that the use of digital technologies in early childhood is of increased importance, particularly given the extent to which images are now "routinely reappropriated, copied, edited and distributed for different purposes" within postmodern and cultural contexts (p. 83). Whilst the educators in this study were keen to use the technology to document and explore learning, Siraj-Blatchford and Whitebread (2003) suggest that digital technologies can be used in the early childhood classroom to help children understand how images and representations of reality can be manipulated by a variety of users. One of the best ways to achieve this understanding is by having children work with and manipulate their own images so that they "become aware of the conditions under which images are produced and become themselves producers of they images they see in cartoons, for example" (p. 83). This idea was noted earlier by teacher three who intended to use the technology to allow the children to manipulate images of themselves and work they had previously generated. Other educators appeared more focused on using digital images as prompts for reflection, or as a means of documenting learning. 
Access to reliable and current technology would seem an obvious factor to consider when integrating computers in the early childhood classroom. However, in those situations where such technology is unavailable, it would appear that using a computer can become too frustrating to have educational worth. In these cases, the effective integration of a computer to the early childhood setting is one defined not some much by the presence of the computer itself, or even pedagogical concerns, as it is related to issues associated with resourcing, access and equity to appropriate educational materials (Wood, Willoughby \& Specht, 1998). Several of the teachers were also able to describe the vision they held for how digital technologies would be integrated into their programs, should they have affordable access to the technology.

\section{Factor four: Location of the computer in the classroom}

The location of the computer in the classroom represented the fourth factor of concern regarding the integration of computers in early childhood education. For two of the educators, this issue was related to access, with the only computer in each centre located in their offices. This raised a number of issues with respect to its use in an educational sense. For teacher three, it meant needing more adults in the centre to supervise those children using the computer in her office; and for teacher eleven it meant wheeling the computer in and out of her office and into the main learning space:

Where it is, it really annoys me that I can't take the computer in there and because my assistant is completely illiterate with computers, well it becomes hard. I guess, some of the parents on duty might be able to do it, but they have to be REALLY comfortable with it to do it, and for me to be out of the room and take two children at a time, it means that my assistant and the parent are left with twenty two other children (T3)

I used to wheel it in and out of the office on days when we were going to use it which was a pain in the neck, or then we used to have parents take children into the office privately, with the door open and that was ok, and that seemed to work better, but it disrupted the children in their normal day to day things because they would be waiting for their turn or it was their turn and they would be in the middle of something else (T11)

These experiences with the computer meant that each of these teachers described the actual location of the computer in the classroom as an important factor to consider with respect to its integration in early childhood education. For those educators with access to more than one computer, the location of the computer was still a factor requiring consideration in order to ensure that it was utilised effectively. In general, the computer was located in relation to existing learning experiences and placed closest to the quieter and literacy based experiences such as the 
book corner. A more pragmatic (but nonetheless crucial) feature was the availability of power outlets in the classroom:

There are limited places where we can put it. Power points is one big factor for us, we have only got a few power points around the room and also I suppose we try to locate it in a fairly, well it is a quiet activity in the same way that books are, so I have located it in an area that is not in the middle of other children's play. So it is in the archive, and it had to go there because that is the only other place where there is a power point (T6)

Initially we had the computer right near the door, and facing right at the doorway and I found that to be not really appropriate condition for many reasons. It was the very first thing that children saw when they walked in the door, so for some children that would be the only thing that they wanted to do, and they weren't experiencing other things in the room, and the other thing was it was very noisy in the entrance way, you know, people coming and going all the time and they weren't able to focus and concentrate on things that they were doing, so I moved it down around the corner so that the children that were doing other things were not distracted by it, and for the children that are working on the computer they're concentrating and they are not being distracted by the others (T3)

We don't want it as a distraction, so we have it near quieter activity areas, maybe like facing a wall, or in a little corner, so children aren't walking all around it and other children, so they are not distracted and it is usually in a quieter area, not like backing onto the block mat or something (T5)

For another educator, the location of the computer was defined by the need to provide the children with enough space to move around the computer. This decision was made with respect to the developmental needs of young children in a physical sense:

We decided to locate it on a wall to have the support and just in case the children were pushing and pulling cords and leads, making them very contained so we had the space, but also in a corner of the room where there was also lots of space around it, so room for chairs and pulling, plus if other children wanted to come and observe, so that was thought through.

The location of the computer in the actual room was of importance to the educators in terms of the children's learning. For those educators with access to only one computer this issue was of perhaps greater importance, since its location in their offices raised difficulties associated with the appropriate supervision of children. For those educators with computers in their classrooms there was a need to locate it in an area where the children would not be distracted by other people. In addition, there were the more obvious limitations due to the location of power points in the room.

However, as a factor requiring consideration, the location of the computer in the classroom was clearly related to the learning that the educators anticipated would occur as the children interacted with the technology. 
Were this not the case, they would not have been as concerned with ensuring that it was located in a space where children were able to work undisturbed, yet also be supervised by the adults in the room. Such concerns have been identified in previous research $\left(\mathrm{O}^{\prime}\right.$ Rourke \& Harrison, 2004) and linked by Stephen \& Plowman (2003) with issues associated with the philosophy of self selection and free play in early childhood education. Stephen and Plowman (2003) suggest that the free play and self selection philosophy underpinning practice in early education means that the computer can be offered to young children as another, yet competing activity for their attention. Its location in the early childhood classroom is therefore of importance given that in situations of prominence young children may be more inclined than older children to "express unconditional preference for using the computer, regardless of the activity" (Selwyn \& Bullon, 2000: cited in Stephen \& Plowman, 2003). The physical location of the computer in the early childhood classroom therefore holds implications for the children's learning in relation to the location of other and perhaps more traditional learning experiences. Here, the educators noted that it needed to be located in quieter areas of the classroom, and yet not distract children from the other learning experiences on offer.

\section{Conclusion}

Research has suggested that computers can be used in developmentally appropriate ways to support young children's learning in early childhood education (Clements \& Sarama, 2002; Finegan \& Austin, 2002 and Rivera, Galarza, Entz \& Tharp, 2002). More research recent has begun to explore how computers are related to the social and educational contexts represented by the early childhood classroom (Brooker, 2003; Plowman \& Stephen, 2005). An important aspect of this research has involved examining how educators themselves conceive of, and use, computers in the early childhood classroom.

The findings from this study appear to support those from existing research indicating that the integration of computers in early childhood education are influenced by a range of factors, including educators' level of computing knowledge, appropriate software selection for young children, access to up to date technology, and issues associated with the location of a computer within the early childhood classroom (Filipenko \& Rolfsen, 1999; Haugland, 1997; Judge, et al., 2004 and Sandberg, 2002). This particular set of factors holds implications for how effectively computers can be used in early childhood education to support children's learning and development.

Whilst each factor is of importance alone, combined the four factors suggest that effective integration of computers into early childhood classrooms involves reflection on their relationship to the existing curricula 
in relation to the various levels of computing skill held by educators. In addition, access to current and reliable computers (and associated technologies such as digital cameras) is crucial to ensure that children and educators are not frustrated in their attempts to use the technology as an additional tool or learning medium in the classroom. As a set of findings, these factors may be useful to those educators planning to integrate a computer in their classroom in order to ensure that the presence of the computer serves to support children's learning experiences within the context of early childhood education.

\section{References}

Anderson, J. (1999). Responses to technological change. In J. Keeves. \& K. Majoribanks (Eds.), Australian Education: Review of Research 1965-1998 (pp. 327353). Melbourne: Australian Council for Educational Research

Australian Early Childhood Association (1999). Information technology and the young child. AECA's policies and working positions (Policy statement). Canberra: Australian Early Childhood Association.

Barnes, B. \& Hill, S. (1983). Should young children work with microcomputers: Lego before logo? The Computing Teacher, 12, 10-14.

Brooker, L. (2003). Integrating new technologies in UK classrooms: Lessons for teachers from early years practitioners. Childhood Education, 79(5), 261-267.

Clements, D. (1999). Young children and technology. Washington, DC: American Association of the Advancement of Science.

Clements, D. \& Sarama, J. (2002). The role of technology in early childhood learning. Teaching Children Mathematics, 8(6), 340-345.

Edwards, S. (2001). Early childhood educators' perceptions of developmentally appropriate interactive multimedia software. Australian Association of Research in Education 2001 Conference Papers, Fremantle, 2-6 December. http://www.aare.edu.au/01pap/edw01068.htm

Filipenko, M. \& Rolfsen, G. (1999). What will it take to get computers into an early childhood classroom? Canadian Children, 24(2), 35-38.

Finegan, C. \& Austin, J. (2002). Developmentally appropriate technology for young children. Information Technology in Childhood Education Annual, 87-102.

Genishi, C., McCollum, P. \& Strand, E. (1985). Research currents: the interactional richness of children's computer use. Language Arts, 62(5), 526-532.

Goodwin, L., Goodwin, W. \& Garel, M. (1996). Use of microcomputers with preschoolers: A review of the literature. Early Childhood Research Quarterly, 1, 269-286.

Haugland, S. (1997). How teachers use computers in early childhood classrooms. Journal of Computing in Childhood Education, 8(1), 3-14.

Haugland, S. (1999). What role should technology play in young children's learning? Young Children, November, 26-43. 
Judge, S., Puckett, K. \& Cabuk, B. (2004). Digital equity: New findings from the early childhood longitudinal study. Journal of Research on Technology in Education, 36(4), 383-396.

Muller, A. \& Perlmutter, M. (1985). Preschool children's problem solving interactions at computers and jigsaw puzzles. Journal of Applied Developmental Psychology, 6, 173-186.

National Association for the Education of Young Children (1996). NAEYC Position statement: Technology and young children. Young Children, 51(6), 11-16.

O'Rourke, M. \& Harrison, C. (2004). The introduction of new technologies: New possibilities for early childhood pedagogy. Australian Journal of Early Childhood, 29(2), 11-18.

Papert, S. (1980). Mindstorms: Children, computers and powerful ideas (Second ed.). London: Harvester Wheatsheaf.

Plowman, L. \& Stephen, C. (2005). Children, play and computers in pre-school education. British Journal of Educational Technology, 36(2), 145-157.

Rivera, H., Galarza, S., Entz, S., Tharp, R. (2002). Technology and pedagogy in early childhood education: Guidance from cultural-historical-activity theory and developmentally appropriate instruction. Information Technology in Childhood Education Annual, 181-204.

Sandberg, A. (2002). Preschool teacher's conceptions of computers and play. Information Technology in Childhood Education Annual, 245-262.

Siraj-Blatchford, J. \& Whitebread, D. (2003). Supporting information and communications technology in the early years. Berkshire, UK: Open University Press.

Stephen, C. \& Plowman, L. (2003). Information and communication technologies in preschool settings: a review of the literature. International Journal of Early Years Education, 11(3), 223-234.

Wood, E., Willoughby, T. \& Specht, J. (1998). What's happening with computer technology in early childhood education settings? Journal of Education Computing Research, 18(3), 237-243.

Wright, J. \& Samaras, A. (1986). Play worlds and microworlds. In P. Campbell. \& G. Fein (Eds), Young children and microcomputers (pp. 74-86). Englewood Cliffs, New Jersey: Prentice Hall.

Yelland, N. (1998). Empowerment and control with technology in the early childhood years. Educational Practice and Theory, 20(2), 45-55.

Yelland, N. (1999). Reconceptualising schooling with technology for the 21st century: images and reflections. Information Technology in Childhood Annual, 3959.

Dr Susan Edwards, Faculty of Education, Monash University Peninsula Campus, McMahons Road, Frankston Vic 3199. Email:

Susan.Edwards@education.monash.edu.au 